\title{
The Effect of Insulin Antibodies on Insulin Dose and Diabetic Control
}

\author{
S. Walford, S. P. Allison and W. G. Reeves \\ Departments of Immunology and Medicine, University Hospital, Nottingham, UK
}

Summary. In a single blind randomised cross-over study, 40 patients were changed from ordinary bovine to highly purified porcine insulins for a period of 6 months. Half were later rechallenged with bovine insulin. Sequential determinations of $\mathrm{IgG}$ insulin binding capacity for bovine insulin were correlated with insulin dose and diabetic control. After changing to highly purified insulins the following correlations were observed between percentage change in insulin dose and change in insulin binding capacity: at 2 months $r=0.35(p<0.05)$, at 4 months $r=0.38$ $(p<0.02)$ and at 6 months $r=0.37(p<0.02)$. When the patients who showed substantial changes in $\mathrm{HbA}_{1}$ were removed from the analysis, the remaining 29 demonstrated a clearer relationship between these two variables $(r=0.56, p<0.01)$. Removal of patients with a low initial insulin binding capacity left 18 patients with stable diabetes, and changes in insulin binding capacity and insulin dose showed an even closer correlation for this group $(r=0.77, p<0.001)$. A similar degree of positive correlation was observed after rechallenge with bovine insulin. We conclude that the level of circulating insulin antibody affects the dose of insulin required to maintain stable diabetic control.

Key words: Insulin, insulin antibody, diabetic control.

Most patients treated with ordinary bovine insulins develop circulating insulin antibodies [1]. Highly purified porcine insulins are much less immunogenic and patients changing to these insulins often experience a reduction in insulin requirement [2,3], a fall in circulating insulin binding capacity [4] and an increase in circulating levels of free insulin [5]. Although antibody mediated insulin resistance is unusual [6], injection site lipoatrophy is a common complication of the use of ordinary bovine insulins [7]. Other possible effects of insulin antibodies are less clear. Andersen [8] showed that the presence of antibodies was associated with a reduction in the honeymoon period independent of the level of diabetic control and the hypothesis that insulin antibody might 'buffer' the effect of circulating insulin [9] has not been substantiated. We report a study of the relationship between changes in insulin antibody, insulin dose and diabetic control in established diabetics changing from ordinary bovine soluble and isophane to highly purified porcine equivalents and the effects of rechallenge with the original insulins.

\section{Patients and Methods}

The practice of one hospital diabetologist was surveyed to identify all the patients aged between 16 and 65 years who had had diabetes for at least 3 years and had been treated regularly with ordinary bovine soluble and isophane insulins for at least that time. Those who were blind or pregnant or who had other serious medical or psychological illness were excluded. Fifty-nine of the 71 eligible patients consented to be studied and 40 completed the 18 month protocol. These 14 women and 26 men were aged between 16 and 64 years (mean 40 years). The age at diagnosis ranged from 2 to 55 years (mean 25 years) and the mean duration of insulin therapy was 15 years ( $3-44$ years). The two patients with detectable levels of C-peptide had values below $0.15 \mathrm{nmol} / 1$.

All the patients were seen by one doctor throughout (SW). A run-in period of 3 months was used to ensure standardisation of injection technique and sensible dietary regulation. Home blood glucose monitoring [10] and regular four-times-daily urine testing were used to correct inappropriate insulin doses and an attempt was made to find the closest degree of diabetic control that the patients could sustain without intolerable alteration of lifestyle or more than two injections of soluble and isophane insulins daily. After randomisation at the second visit half the patients continued to use ordinary bovine insulins and the others changed to highly purified porcine insulins (Actrapid and Monotard - Novo) which were dispensed in identical containers. In view of the frequency of serious 
hypoglycaemia reported from another study [5], all patients were advised to make a $10 \%$ dose reduction at this visit and in the 2 months following cross-over doses were adjusted largely on the patient's initiative, depending on the results of four daily urine tests and hypoglycaemic attacks which were recorded on diary cards. Ten or 11 glucose measurements were performed on at least 2 days at the time of every clinic visit and insulin adjusted to try to sustain a stable level of control. Patients attended at 2 monthly intervals for 6 months after cross-over. Blood was collected for $\mathrm{HbA}_{1}$ and insulin antibody determination. After 6 months, the group who had continued to use bovine soluble and isophane were crossed to purified porcine insulins and the group who had received 6 months porcine insulin therapy were rechallenged with the original bovine in sulins. The trial continued for three more visits at two monthly intervals.

$\mathrm{HbA}_{1}$ was measured by small column chromatography (BioRad Laboratories, Richmond, California) with temperature regulated at $21^{\circ}-23^{\circ} \mathrm{C}$. EDTA blood samples were stored for $4-6 \mathrm{~h}$ at room temperature $\left(18^{\circ}-20^{\circ} \mathrm{C}\right)$ and a further $48 \mathrm{~h}$ at $4^{\circ} \mathrm{C}$ before assay in an attempt to reduce the effect of short-term changes in blood glucose. The age and sex structured normal range was 7.0\% (SD $1.1 \%$ ) of total haemoglobin. The coefficient of variation of the assay was $5 \%$ (intra-batch) and $8.2 \%$ (between batches).

The Ig G insulin binding capacity was measured immunochemically as previously described [11]. Iodinated bovine insulin (IM32) was obtained from the Radiochemical Centre, Amersham, UK and sequential samples from each patient were measured together in the same batch. Results are expressed as $\mu \mathrm{g}$ of insulin bound per litre of serum.

\section{Results}

Before cross-over, insulin binding capacity ranged from 1 to $59 \mu \mathrm{g} / 1$ with a median of $6.2 \mu \mathrm{g} / 1$. Insulin binding capacity (IBC) remained stable if treatment was unchanged. There was no relationship between insulin binding capacity, insulin dose or $\mathrm{HbA}_{1}$ at the outset of the study.

\section{Transfer from Bovine to Porcine Insulin}

Observations 2, 4 and 6 months after the change from ordinary to highly purified porcine insulin were used to derive changes in insulin binding capacity and $\mathrm{HbA}_{1}$ and the percentage change in insulin dose. These data are summarised in Table 1 . The deterioration in control seen at the visit 2 months after crossover reflects the $10 \%$ dose reduction which was made when the patients changed to porcine insulin. In many, this was inappropriate and was gradually corrected so that by 4 months the $\mathrm{HbA}_{1}$ values which inevitably lagged behind the dose alterations by several weeks, were back to starting levels. Patients with higher insulin binding capacities experienced larger absolute reductions: the fall being of the order of $30 \%$ of the original level after 4 months. When the changes in insulin binding capacity were calculated as a percentage of the initial value, it was found that $58 \%$ of the reduction occurred in the first 2 months and $80 \%$ by 4 months. Correspondingly, $40 \%$ of the dose reduction occurred in the first 2 months and $80 \%$ by 4 months.

The relationship between the change in insulin binding capacity and percentage change in insulin dose was examined for the whole group at 2, 4 and 6 months after cross-over (Table 1). Significant correlations were found at each data point although correlation coefficients were low. In contrast, no relationship was seen between the change in $\mathrm{HbA}_{1}$ and change in insulin binding capacity. In order to examine the interaction of these three variables more carefully, patients whose $\mathrm{HbA}_{1}$ changed by more than 1.5 standard deviations of the between batch variation (representing a change of more than $1.4 \%$ at an $\mathrm{HbA}_{1}$ of $12 \%$ were identified. In these patients there was a clear negative correlation between change in $\mathrm{HbA}_{1}$ and percentage change in dose $(r=-0.98 ; p<0.001$ at 4 months) suggesting that the instability of these patients was closely associated with changes in their insulin dose. The correlation between change in insulin binding capacity and percentage change in dose in the remaining 29 patients was closer than for the group as a whole (stable control group, Table 1).

A further segregation of the data was performed to exclude those patients whose insulin binding capacity changed by less than $1 \mu \mathrm{g} / \mathrm{l}$. At the 4 month visit this left 18 patients with stable levels of $\mathrm{HbA}_{1}$ and changes of insulin binding capacity of greater than $1 \mu \mathrm{g} / 1$. In this group who exhibited both stable control and change in antibody, the correlation of changes in dose and insulin binding capacity became even clearer at 4 or 6 months: $r=0.77 ; p<0.001$ and $r=0.76$; $p<0.001$, respectively (Table 1, Fig. 1).

\section{Rechallenge with Bovine Insulin}

Eighteen patients were rechallenged with bovine insulin presented in identical vials so that patients were unaware of the change. Changes in insulin binding capacity and $\mathrm{HbA}_{1}$ and percentage change in dose are summarised in Table 2 . There was no obligatory dose change at this cross-over and the deterioration in control at 2 months was a reflection both of failure to make appropriate dose increases and of the rapid rise in insulin binding capacity. In contrast to the bovine to porcine cross-over, where falls in insulin binding capacity were gradual, the rise seen on rechallenge was more rapid with $74 \%$ of the increase occurring within 2 months. In the same period only $46 \%$ of the final dose increase occurred. At 4 months the $\mathrm{HbA}_{1}$ levels again lagged behind the change in dose so that it was not until 6 months that the $\mathrm{HbA}_{1}$ had returned close to starting values.

The relationship between percentage change in dose and change in insulin binding capacity for the 
Table 1. Changes in insulin dose, insulin binding capacity $(\triangle \mathrm{IBC})$ and $\left.\mathrm{HbA}_{1}(\triangle \mathrm{HbA})_{1}\right)$ at 2,4 and 6 months after cross-over from ordinary bovine to highly purified porcine insulins

\begin{tabular}{|c|c|c|c|c|}
\hline & & $0-2$ months & $0-4$ months & $0-6$ months \\
\hline \multirow[t]{2}{*}{ All patients $(n=40)$} & $\begin{array}{l}\% \text { change in dose } \\
\triangle \mathrm{IBC} \\
\triangle \mathrm{HbA}_{\mathrm{I}}\end{array}$ & $\begin{array}{r}-3.5 \pm 2.2 \\
-2.1 \pm 0.7 \\
0.6 \pm 0.24\end{array}$ & $\begin{array}{ll}-6.2 & \pm 2.7 \\
-2.5 & \pm 0.9 \\
0.004 & \pm 0.25\end{array}$ & $\begin{aligned}-9.1 & \pm 2.8 \\
-2.9 & \pm 1.00 \\
0.23 & \pm 0.28\end{aligned}$ \\
\hline & \% change in dose $\times \triangle \mathrm{IBC}: r$ & $\begin{array}{r}0.35 \\
<0.05\end{array}$ & $\begin{array}{r}0.38 \\
<0.02\end{array}$ & $\begin{array}{r}0.37 \\
<0.02\end{array}$ \\
\hline Stable control group & $\%$ change in dose $\times \triangle \mathrm{IBC}: \underset{r}{p}, \frac{r}{n}$ & $\begin{array}{r}0.46 \\
<0.02 \\
29\end{array}$ & $\begin{array}{r}0.56 \\
<0.01 \\
29\end{array}$ & $\begin{array}{r}0.49 \\
<0.01 \\
31\end{array}$ \\
\hline $\begin{array}{l}\text { Group showing stable } \\
\text { control and change in } \\
\text { antibody level }\end{array}$ & $\%$ change in dose $\times \Delta \mathrm{IBC}: \underset{p}{p}, \frac{r}{n}$ & $\begin{array}{l}0.42 \\
\mathrm{NS}(<0.1) \\
\quad 18\end{array}$ & $\begin{aligned} & 0.77 \\
< & 0.001 \\
& 18\end{aligned}$ & $\begin{array}{c}0.76 \\
<0.001 \\
16\end{array}$ \\
\hline
\end{tabular}

Results expressed as mean $\pm \mathrm{SEM}$

Table 2. Changes in insulin dose, insulin binding capacity $(\triangle \mathrm{IBC})$ and $\mathrm{HbA}_{1}\left(\Delta \mathrm{HbA}_{1}\right)$ at 2,4 and 6 months after rechallenge with bovine insulins

\begin{tabular}{|c|c|c|c|c|}
\hline & & $0-2$ months & $0-4$ months & $0-6$ months \\
\hline \multirow{4}{*}{$\begin{array}{l}\text { All patients rechallenged } \\
(n=18)\end{array}$} & $\%$ change in dose & $+4.6 \pm 2.8$ & $+9.0 \pm 3.3$ & $+7.7 \pm 2.8$ \\
\hline & $\begin{array}{l}\triangle \mathrm{IBC} \\
\triangle \mathrm{HbA}_{1}\end{array}$ & $\begin{array}{l}+3.4 \pm 1.5 \\
+0.55 \pm 0.26\end{array}$ & $\begin{array}{l}+2.7 \pm 1.1 \\
+0.54 \pm 0.33\end{array}$ & $\begin{array}{l}+3.2 \pm 1.3 \\
+0.08 \pm 0.33\end{array}$ \\
\hline & $\%$ change in dose $\times \Delta \mathrm{IBC}: r$ & $\begin{array}{r}0.61 \\
<0.01\end{array}$ & $\begin{array}{l}0.17 \\
\mathrm{NS}(>0.1)\end{array}$ & $\begin{array}{r}0.61 \\
<0.01 \\
\end{array}$ \\
\hline & & \multicolumn{3}{|c|}{ Data at peak IBC } \\
\hline $\begin{array}{l}\text { Stable control group } \\
(n=14)\end{array}$ & $\%$ change in dose $\times \triangle \mathrm{IBC}: \frac{r}{p}$ & \multicolumn{3}{|c|}{$\begin{array}{r}0.69 \\
<0.01 \\
\end{array}$} \\
\hline $\begin{array}{l}\text { Group showing stable } \\
\text { control and change in } \\
\text { antibody }(n=11)\end{array}$ & $\%$ change in dose $\times \Delta \mathrm{IBC}: \frac{r}{p}$ & \multicolumn{3}{|c|}{$\begin{aligned} & 0.89 \\
< & 0.001\end{aligned}$} \\
\hline
\end{tabular}

Results expressed as mean $\pm \mathrm{SEM}$

group as a whole is significant at 2 months $(r=0.61$ $p<0.01)$ and 6 months $(r=0.61 ; p<0.01)$ but not at 4 months (Table 2 ). In view of the different time course of the response compared with the first part of the study and the smaller number of patients, data taken from the visit at which the peak insulin binding capacity was achieved have been used for further analysis. The 14 patients with stable control (as defined previously) then show a similar degree of correlation between change in insulin binding capacity and percentage change in dose $(r=0.69 ; p<0.01$, Table 2$)$. When the further three patients with changes in insulin binding capacity of less than $1 \mu \mathrm{g} / 1$ are removed, the 11 remaining stable responders show a correlation between change in insulin binding capacity and percentage change in dose which is much closer $(r=0.89$; $p<0.001$ ) as in the first half of the study (Table2, Fig. 1).
The data from both parts of the study have been combined in Figure 1 as the regression equations for the two parts are not significantly different. The combined data demonstrate that whether the insulin binding capacity was increased or decreased, the associated percentage change in insulin dose required to maintain stable control was of the same order.

\section{Discussion}

Several studies have examined the effect of changing from ordinary bovine to highly purified porcine insulin preparations. Of seven reports which examined the relationship between dose reductions and changes in insulin binding capacity, four [5, 12-14] did and three $[2,4,15]$ did not show an association. These studies all failed to take account of changes in 


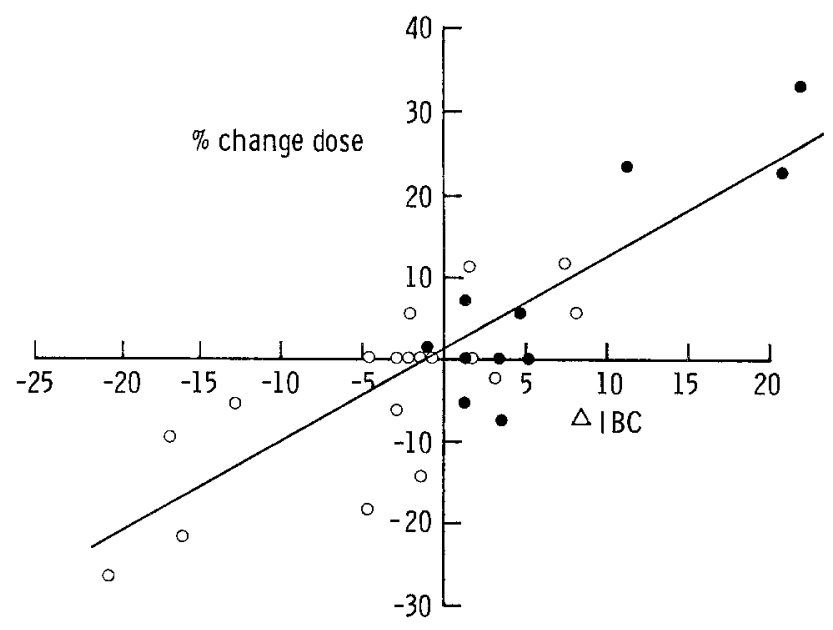

Fig. 1. Graph of percentage change in dose against change in $\mathrm{IgG}$ insulin binding capacity $(\triangle \mathrm{IBC})$ for patients with stable control and change in antibody level, on switching from bovine to porcine insulin and vice versa.

$\circ=$ bovine $\rightarrow$ porcine insulin, $\bullet=$ porcine $\rightarrow$ bovine insulin

diabetic control occurring during the study period, principally because $\mathrm{HbA}_{1}$ assays were not available. Our data shows significant correlation between changes in insulin dose and antibody binding capacity 2, 4 and 6 months after cross-over to highly purified insulin. In the group as a whole, the relationship is not a strong one and it is legitimate to try and isolate other variables. The aim of this study was to maintain stable diabetic control but this was not achieved in some patients. A change in $\mathrm{HbA}_{1}$ was used to identify these patients because urine test results may be an unreliable index [16]. Blood glucose profiles were obtained on only 2 days in each 2 month period and although the mean blood glucose did correlate significantly with $\mathrm{HbA}_{1}$ values, the correlation coefficient was low and the profiles showed considerable day-to-day variation. $\mathrm{HbA}_{1}$ values, although internally consistent, did not exclude the effects of short-term changes in blood glucose and were not therefore a perfect index of overall mean blood glucose. The change in $\mathrm{HbA}_{1}$ used as the cut off point excludes $70 \%$ of any assay variation. When this third variable is considered and large variations in control are excluded from analysis, the relationship between changes in insulin dose and insulin binding capacity becomes stronger at every data point.

This study also emphasises the heterogeneity of immune responsiveness to injected insulins which is associated with certain HLA phenotypes [17]. Our patients with low initial insulin binding capacities did not respond to a change of insulin type either by a change in dose, diabetic control or insulin binding capacity. In a study principally concerned with the rela- tionship between insulin dose and insulin antibody it was considered justifiable to explore the effect of removing such patients from analysis. The remaining sub-group of diabetics with stable levels of $\mathrm{HbA}_{1}$ who experience substantial changes in insulin binding capacity exhibit a clear association between this and the change in insulin dose required to maintain control. The relationship is similar both for changing to highly purified insulin and for rechallenge with ordinary bovine preparations.

This analysis suggests that conflicting conclusions in earlier studies are largely due to failure to allow for fluctuations in control. In our unstable patients the change in $\mathrm{HbA}_{1}$ was inversely related to the observed change in dose and this relationship tended to mask the positive correlation of dose changes with changes in insulin binding capacity. These considerations also emphasise the problem of predicting the dose reduction for an individual patient whose antibody status is unknown. A patient with a very low insulin binding capacity on treatment with ordinary bovine insulins is likely to be unaffected by a change to highly purified porcine insulins whilst patients with higher initial insulin binding capacities will experience a fall of about $30 \%$ with a concomitant reduction of insulin requirement to sustain stable control. We would expect similar problems to arise in assessing dose changes when highly purified human insulins are given to patients stabilised on ordinary bovine preparations.

The rapid rise in insulin binding capacity after rechallenge with ordinary bovine insulin, often to a level exceeding that at the start of the study, is typical of a secondary immune response. There is an associated increase in insulin requirement to maintain control. The relationship between the two variables is of the same order as the reduction seen on initial transfer to purified insulins. Studies in vitro have demonstrated the ability of insulin antibody to block insulin: insulin receptor interaction [18]. The results of the present study are compatible with this idea. Upward and downward changes in insulin binding capacity are associated with changes in insulin requirement to maintain control and show a predictable and highly significant pattern of correlation. The data suggest that insulin antibodies alter diabetic control by reducing the availability of administered insulin.

Acknowledgements. SW was supported by Novo Laboratories (UK) who also supplied specially packaged $\mathrm{MC}$ insulins. $\mathrm{HbA}$ kits were generously donated by Bio-Rad Laboratories, Richmond, California. We thank the Trustees of Nottingham General Hospital, the Novo Research Institute, the British Diabetic Association and Boehringer Mannheim for financial support and Dr. R. B. Tattersall for helpful discussion. We also thank M. Villiers and U. Kelly for technical assistance, J. Davison and I. Deverill for their assistance with data processing and statistical analysis and A. Willington for preparing the manuscript. 


\section{References}

1. Reeves WG (1980) Immunology of diabetes and insulin therapy. In: Thompson RA (ed) Recent advances in clinical immunology, 2. Churchill Livingstone, Edinburgh London New York, pp 183-220

2. Oakley NW (1976) Effect of 'fractionated' insulins on total plasma insulin binding capacity and insulin requirement in severe diabetes. Lancet 1:994-996

3. Griffin NK, Smith MA, Baum JD (1979) Reduction of insulin dose on changing diabetic children from standard to monocomponent insulins. Arch Dis Child 54: 123-126

4. Mustaffa BE, Dagget PR, Nabarro JDN (1977) Insulin binding capacity in patients changed from conventional to highly purified insulins. Diabetologia 13:311-315

5. Asplin CM, Hartog M, Goldie DJ (1978) Change of insulin dosage, circulating free and bound insulin and insulin antibodies on transferring diabetics from conventional to highly purified porcine insulin. Diabetologia 14:99-105

6. Shipp JC, Cunningham RW, Russell RO, Marble A (1965) Insulin resistance: clinical features, natural course and effects of adrenal steroid treatment. Medicine (Baltimore) 44: 165

7. Reeves WG, Allen BR, Tattersall RB (1980) Insulin-induced lipoatrophy: evidence for an immune pathogenesis. $\mathrm{Br}$ Med J 280: $1500-1503$

8. Andersen OO (1976) Clinical significance of anti-insulin antibodies. Acta Endocrinol (Suppl) 205: 231-240

9. Dixon K, Exon PD, Malins JM (1975) Insulin antibodies and control of diabetes. Q J Med 44: 543-553

10. Walford S, Gale EAM, Allison SP, Tattersall RB (1978) Selfmonitoring of blood glucose. Lancet 1:732-735

11. Reeves WG, Kelly U (1980) An immunochemical method for the quantitation of insulin antibodies. J Immunol Methods 34: $329-338$
12. Yue DK, Turtle JR (1977) New forms of insulin and their use in the treatment of diabetes. Diabetes 26:341-345

13. Bruni B, D'Alberto M, Osenda M, Ricci C, Turco GL (1973) Clinical trial with monocomponentlente insulins. Diabetologia 9: 492-498

14. Klaff LJ, Vinik AI, Berelowitz M, Jackson WPU (1978) Circulating antibodies in diabetics treated with conventional and purified insulins. S Afr Med J 54: 149-153

15. Andreani D, Iavicoli M, Tamburrano G, Menzinger G (1974) Comparative trials with monocomponent and monospecies pork insulins in the treatment of diabetes mellitus. Influence of antibody levels on insulin requirement and on some complications. Horm Metab Res 6: 447-454

16. Tattersall RB, Walford S, Peacock I, Gale E, Allison S (1980) A critical evaluation of methods of monitoring diabetic control. Diabetes Care 3: 150-154

17. Schernthaner G, Ludwig H, Mayr WR (1979) Immunoglobulin $\mathrm{G}$ - insulin antibodies and immune region associated alloantigens in insulin dependent diabetes mellitus. J Clin Endocrinol Metab 48: 403-407

18. de Pirro R, Fusco A, Spallone L, Magnatta R, Lauro R (1980) Insulin antibodies prevent insulin-receptor interactions. Diabetologia 19: $118-122$

Received: 20March 1981

and in revised form: 9 October 1981

Dr. W. G. Reeves

Department of Immunology

University Hospital

Nottingham NG7 2UH, UK 